\title{
Do Internal and External Surfaces of Metal-Organic Frameworks Have the Same Hydrophobicity? Insights from Molecular Simulations
}

\author{
Alexander von Wedelstedt, ${ }^{\dagger}$ Haoyuan Chen, ${ }^{\ddagger}$ Grit Kalies, ${ }^{\dagger}$ and Randall Q. Snurr ${ }^{*, \ddagger}$ \\ $\dagger$ Department of Chemical Engineering, HTW University of Applied Sciences Dresden, \\ 01069 Dresden, Germany \\ $\ddagger$ Department of Chemical and Biological Engineering, Northwestern University, Evanston, \\ Illinois 60208, USA
}

E-mail: snurr@northwestern.edu 


\section{Contents}

S1 General Simulation Information . . . . . . . . . . . . . . S S2

S2 Interatomic Potential Parameters . . . . . . . . . . . . . . . S3

S3 Trial Move Probabilities for Monte Carlo Simulations . . . . . . . . S8

S4 Grand Canonical Monte Carlo Simulation Parameter . . . . . . . . . S9

S5 Monte Carlo Cycles . . . . . . . . . . . . . . . . . . . . . . . . S11

S6 Equation for Calculating Contact Angles . . . . . . . . . . . . . S12

S7 Density Plots . . . . . . . . . . . . . . . . . . . . . . . S13

S8 Calculation Data . . . . . . . . . . . . . . . . . S15

S9 Finite-Size Effect . . . . . . . . . . . . . . . . . . . S16

S10 Adsorption Isotherms . . . . . . . . . . . . . . . . . . S18

S11 Adsorption Surfaces . . . . . . . . . . . . . . . . . . S19

References . . . . . . . . . . . . . . . . . . . . S19

\section{S1 General Simulation Information}

\begin{tabular}{l|cccc}
\hline Surface Model & Simulation Box Size (x y z) & Atom No. & Thickness & Equilibration Time \\
\hline MOF-5-phenyl & $310 \AA \times 300 \AA \times 310 \AA$ & 92736 & $33.8 \AA$ & $4 \mathrm{~ns}$ \\
MOF-5-benzoic & $310 \AA \times 300 \AA \times 310 \AA$ & 94464 & $33.8 \AA$ & $5 \mathrm{~ns}$ \\
CAU-10-phenyl & $215 \AA \times 300 \AA \times 206 \AA$ & 93600 & $30.0 \AA$ & $5 \mathrm{~ns}$ \\
CAU-10-benzoic & $215 \AA \times 300 \AA \times 206 \AA$ & 96000 & $30.0 \AA$ & $5 \mathrm{~ns}$ \\
CAU-10-open & $236 \AA \times 300 \AA \times 236 \AA$ & 91960 & $25.4 \AA$ & $4 \mathrm{~ns}$ \\
\hline
\end{tabular}

Table S1: Simulation settings concerning the surface models. 


\section{S2 Interatomic Potential Parameters}

(a)

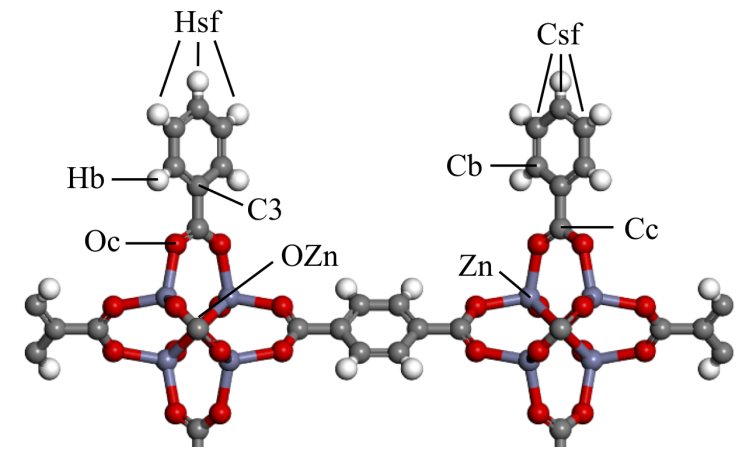

(b)

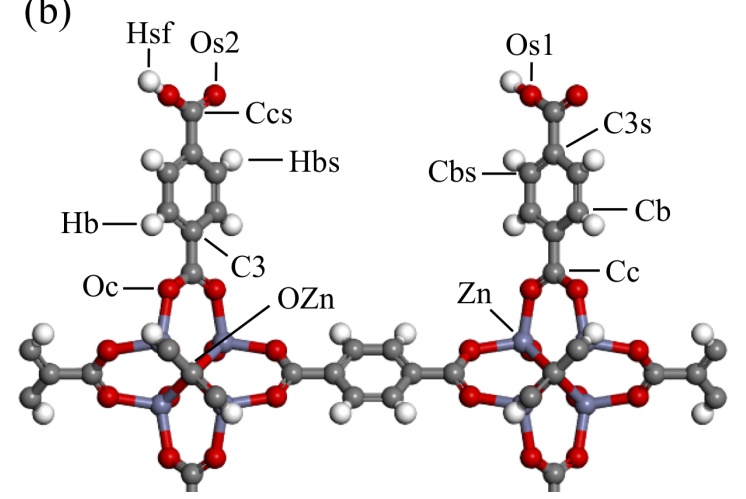

Figure S1: Atom types used to describe (a) MOF-5-phenyl and (b) MOF-5-benzoic.

\begin{tabular}{c|ccc}
\hline Atom Type & $\begin{array}{c}\text { L-J well depth } \\
{[\mathrm{kcal} / \mathrm{mole}]}\end{array}$ & $\begin{array}{c}\text { L-J distance } \\
{[\AA]}\end{array}$ & partial charge \\
\hline $\mathrm{Cb}$ & 0.0951 & 3.473 & -0.102 \\
$\mathrm{Cc}$ & 0.0951 & 3.473 & 0.373 \\
$\mathrm{C} 3$ & 0.0951 & 3.473 & 0.051 \\
$\mathrm{Csf}$ & 0.0951 & 3.473 & -0.09 \\
$\mathrm{Hb}$ & 0.0152 & 2.846 & 0.149 \\
$\mathrm{Hsf}$ & 0.0152 & 2.846 & 0.105 \\
Oc & 0.0957 & 3.033 & -0.499 \\
OZn & 0.06 & 3.118 & -0.87 \\
Zn & 0.124 & 2.462 & 0.942 \\
\hline
\end{tabular}

Table S2: Interaction parameters for the atom types in MOF-5-phenyl. 


\begin{tabular}{c|ccc}
\hline Atom Type & $\begin{array}{c}\text { L-J well depth } \\
{[\mathrm{kcal} / \mathrm{mole}]}\end{array}$ & $\begin{array}{c}\text { L-J distance } \\
{[\AA]}\end{array}$ & partial charge \\
\hline $\mathrm{Cb}$ & 0.0951 & 3.473 & -0.084 \\
$\mathrm{Cc}$ & 0.0951 & 3.473 & 0.407 \\
$\mathrm{C} 3$ & 0.0951 & 3.473 & 0.044 \\
$\mathrm{Cbs}$ & 0.0951 & 3.473 & -0.095 \\
Ccs & 0.0951 & 3.473 & 0.417 \\
$\mathrm{C} 3 \mathrm{~s}$ & 0.0951 & 3.473 & 0.048 \\
$\mathrm{Hb}$ & 0.0152 & 2.846 & 0.14 \\
$\mathrm{Hbs}$ & 0.0152 & 2.846 & 0.108 \\
$\mathrm{Hsf}$ & 0.0152 & 2.846 & 0.503 \\
Oc & 0.0957 & 3.033 & -0.518 \\
Os1 & 0.0957 & 3.033 & -0.631 \\
Os2 & 0.0957 & 3.033 & -0.398 \\
OZn & 0.06 & 3.118 & -0.877 \\
Zn & 0.124 & 2.462 & 0.929 \\
\hline
\end{tabular}

Table S3: Interaction parameters for the atom types in MOF-5-benzoic.
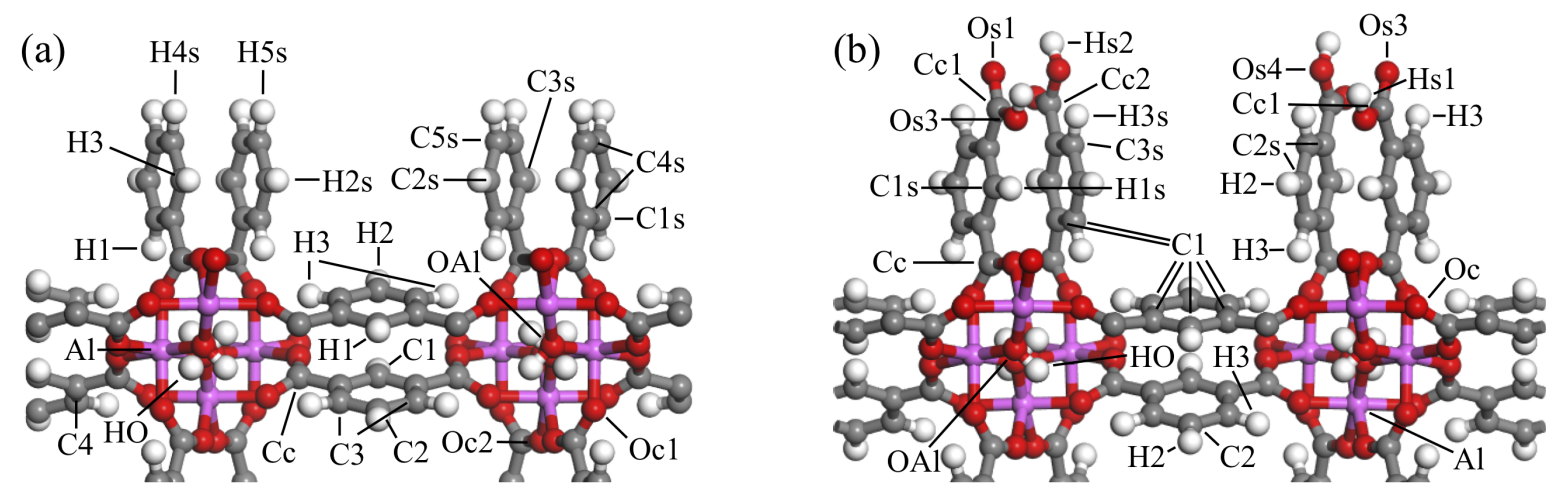

Figure S2: Atom types used to describe (a) CAU-10-phenyl and (b) CAU-10-benzoic. 


\begin{tabular}{|c|c|c|c|}
\hline Atom Type & $\begin{array}{l}\text { L-J well depth } \\
\text { [kcal/mole] }\end{array}$ & $\begin{array}{c}\text { L-J distance } \\
{[\AA]}\end{array}$ & partial charge \\
\hline $\mathrm{Al}$ & 0.505 & 4.008 & 1.362 \\
\hline $\mathrm{C} 1$ & 0.0951 & 3.473 & -0.08 \\
\hline $\mathrm{C} 1 \mathrm{~s}$ & 0.0951 & 3.473 & -0.078 \\
\hline $\mathrm{C} 2$ & 0.0951 & 3.473 & -0.096 \\
\hline $\mathrm{C} 2 \mathrm{~s}$ & 0.0951 & 3.473 & -0.089 \\
\hline C3 & 0.0951 & 3.473 & -0.073 \\
\hline C3s & 0.0951 & 3.473 & -0.083 \\
\hline $\mathrm{C} 4$ & 0.0951 & 3.473 & -0.061 \\
\hline $\mathrm{C} 4 \mathrm{~s}$ & 0.0951 & 3.473 & -0.122 \\
\hline $\mathrm{C} 5 \mathrm{~s}$ & 0.0951 & 3.473 & -0.085 \\
\hline $\mathrm{Cc}$ & 0.0951 & 3.473 & 0.552 \\
\hline $\mathrm{H} 1$ & 0.0152 & 2.846 & 0.165 \\
\hline $\mathrm{H} 2$ & 0.0152 & 2.846 & 0.115 \\
\hline $\mathrm{H} 2 \mathrm{~s}$ & 0.0152 & 2.846 & 0.109 \\
\hline H3 & 0.0152 & 2.846 & 0.133 \\
\hline $\mathrm{H} 4 \mathrm{~s}$ & 0.0152 & 2.846 & 0.104 \\
\hline $\mathrm{H} 5 \mathrm{~s}$ & 0.0152 & 2.846 & 0.097 \\
\hline $\mathrm{HO}$ & 0.044 & 2.571 & 0.296 \\
\hline $\mathrm{OAl}$ & 0.06 & 3.118 & -0.713 \\
\hline Oc1 & 0.0957 & 3.033 & -0.559 \\
\hline Oc2 & 0.0957 & 3.033 & -0.516 \\
\hline
\end{tabular}

Table S4: Interaction parameters for the atom types in CAU-10-phenyl. 


\begin{tabular}{|c|c|c|c|}
\hline Atom Type & $\begin{array}{l}\text { L-J well depth } \\
\text { [kcal/mole }]\end{array}$ & $\begin{array}{c}\text { L-J distance } \\
{[\AA]}\end{array}$ & partial charge \\
\hline $\mathrm{Al}$ & 0.505 & 4.008 & 1.41 \\
\hline $\mathrm{C} 1$ & 0.0951 & 3.473 & -0.068 \\
\hline $\mathrm{C} 1 \mathrm{~s}$ & 0.0951 & 3.473 & -0.051 \\
\hline $\mathrm{C} 2$ & 0.0951 & 3.473 & -0.099 \\
\hline $\mathrm{C} 2 \mathrm{~s}$ & 0.0951 & 3.473 & -0.094 \\
\hline C3s & 0.0951 & 3.473 & -0.059 \\
\hline $\mathrm{Cc}$ & 0.0951 & 3.473 & 0.575 \\
\hline $\mathrm{Cc} 1$ & 0.0951 & 3.473 & 0.459 \\
\hline $\mathrm{Cc} 2$ & 0.0951 & 3.473 & 0.472 \\
\hline H1 & 0.0152 & 2.846 & 0.188 \\
\hline $\mathrm{H} 2$ & 0.0152 & 2.846 & 0.115 \\
\hline H3 & 0.0152 & 2.846 & 0.142 \\
\hline H3s & 0.0152 & 2.846 & 0.163 \\
\hline $\mathrm{HO}$ & 0.044 & 2.571 & 0.299 \\
\hline Hs1 & 0.0152 & 2.846 & 0.331 \\
\hline Hs2 & 0.0152 & 2.846 & 0.301 \\
\hline $\mathrm{Oc}$ & 0.0957 & 3.033 & -0.57 \\
\hline $\mathrm{OAl}$ & 0.06 & 3.118 & -0.723 \\
\hline Os1 & 0.0957 & 3.033 & -0.425 \\
\hline Os2 & 0.0957 & 3.033 & -0.466 \\
\hline Os3 & 0.0957 & 3.033 & -0.45 \\
\hline Os4 & 0.0957 & 3.033 & -0.427 \\
\hline
\end{tabular}

Table S5: Interaction parameters for the atom types in CAU-10-benzoic. 
(a)

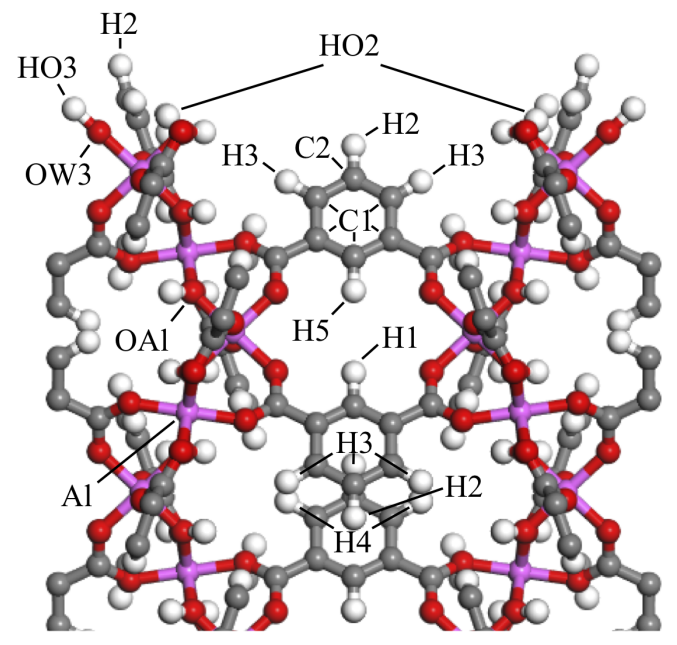

(b)

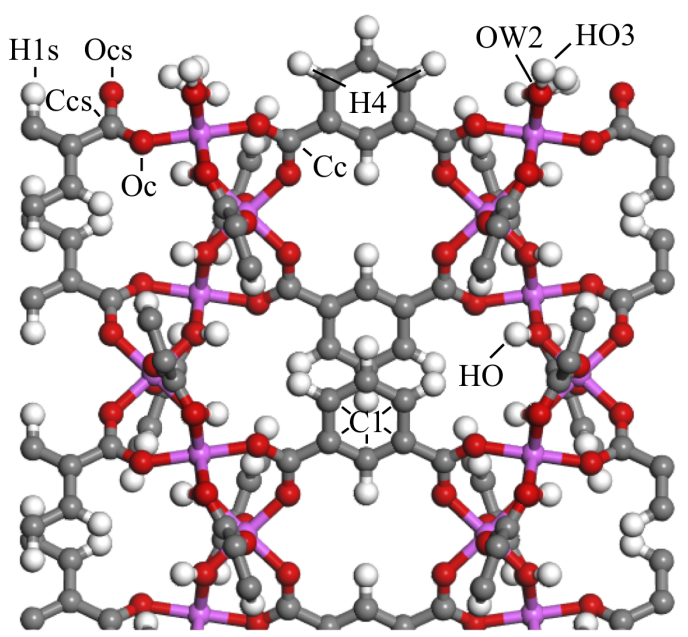

Figure S3: Atom types used to describe CAU-10-open (a) front view (b) side view.

\begin{tabular}{c|ccc}
\hline Atom Type & $\begin{array}{c}\text { L-J well depth } \\
{[\mathrm{kcal} / \mathrm{mole}]}\end{array}$ & $\begin{array}{c}\text { L-J distance } \\
{[\AA]}\end{array}$ & partial charge \\
\hline $\mathrm{Al}$ & 0.505 & 4.008 & 1.362 \\
$\mathrm{C} 1$ & 0.0951 & 3.473 & -0.069 \\
$\mathrm{C} 2$ & 0.0951 & 3.473 & -0.095 \\
$\mathrm{Cc}$ & 0.0951 & 3.473 & 0.553 \\
$\mathrm{Ccs}$ & 0.0951 & 3.473 & 0.493 \\
$\mathrm{H} 1$ & 0.0152 & 2.846 & 0.173 \\
$\mathrm{H} 1 \mathrm{~s}$ & 0.0152 & 2.846 & 0.154 \\
$\mathrm{H} 2$ & 0.0152 & 2.846 & 0.103 \\
$\mathrm{H} 3$ & 0.0152 & 2.846 & 0.127 \\
$\mathrm{H} 4$ & 0.0152 & 2.846 & 0.139 \\
$\mathrm{H} 5$ & 0.0152 & 2.846 & 0.158 \\
$\mathrm{HO}$ & 0.044 & 2.571 & 0.296 \\
$\mathrm{HO} 2$ & 0.044 & 2.571 & 0.387 \\
\hline
\end{tabular}




\begin{tabular}{c|ccc} 
HO3 & 0.044 & 2.571 & 0.312 \\
OAl & 0.06 & 3.118 & -0.713 \\
Oc & 0.0957 & 3.033 & -0.55 \\
Ocs & 0.0957 & 3.033 & -0.445 \\
OW2 & 0.06 & 3.118 & -0.535 \\
OW3 & 0.06 & 3.118 & -0.27 \\
\hline
\end{tabular}

Table S6: Interaction parameters for the atom types in CAU-10-open.

\section{S3 Trial Move Probabilities for Monte Carlo Simulations}

\section{Grand canonical Ensemble}

Translation:

Rotation:

Full regrowth:

Partial regrowth

Swap:

Widom Insertion
0.15

0.15

0.05

0.05

0.5

0.1

\section{Canonical Ensemble}

Translation: $\quad 0.3$

Rotation: $\quad 0.3$

Full regrowth: $\quad 0.1$

Partial regrowth $\quad 0.1$

Swap: $\quad 0.0$

Widom Insertion: $\quad 0.2$ 


\section{S4 Grand Canonical Monte Carlo Simulation Parameter}

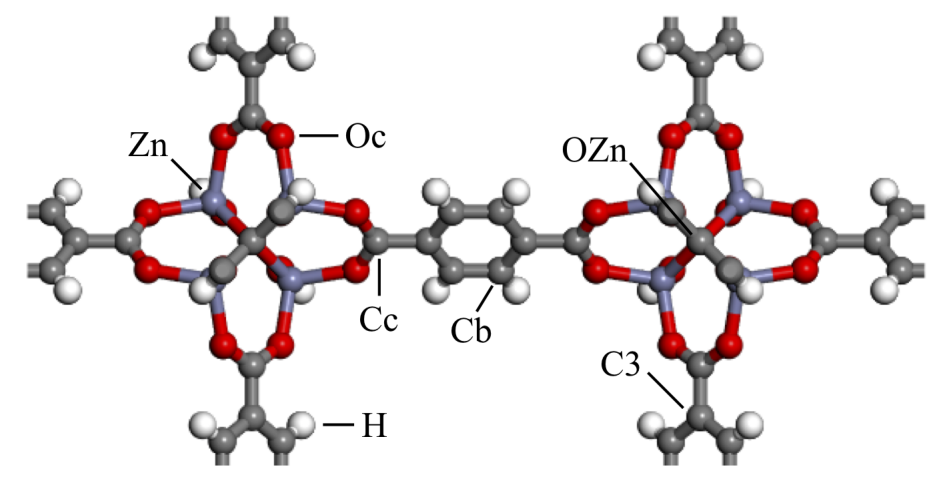

Figure S4: Atom types used to describe MOF-5.

\begin{tabular}{c|ccc|c}
\hline Atom Type & $\begin{array}{c}\text { L-J well depth } \\
{[\mathrm{K}]}\end{array}$ & $\begin{array}{c}\text { L-J distance } \\
{[\AA]}\end{array}$ & $\begin{array}{c}\text { partial charge } \\
\text { DDEC charge }\end{array}$ & $\begin{array}{c}\text { D } \\
\text { (Sladekova et al. }^{1} \text { ) }\end{array}$ \\
\hline $\mathrm{Cb}$ & 47.856 & 3.473 & -0.180 & -0.1237 \\
$\mathrm{Cc}$ & 47.856 & 3.473 & 0.529 & 0.5786 \\
$\mathrm{C} 3$ & 47.856 & 3.473 & 0.023 & -0.0139 \\
$\mathrm{H}$ & 7.649 & 2.846 & 0.223 & 0.1490 \\
$\mathrm{Oc}$ & 48.158 & 3.033 & -0.546 & -0.5512 \\
OZn & 30.193 & 3.118 & -0.946 & -1.0220 \\
Zn & 62.139 & 2.462 & 0.918 & 0.9864 \\
\hline
\end{tabular}

Table S7: Interaction parameters for the atom types in MOF-5 and comparison of the used partial charges with Density Derived Electrostatic and Chemical (DDEC) charges from Sladekova et al. ${ }^{1}$ 


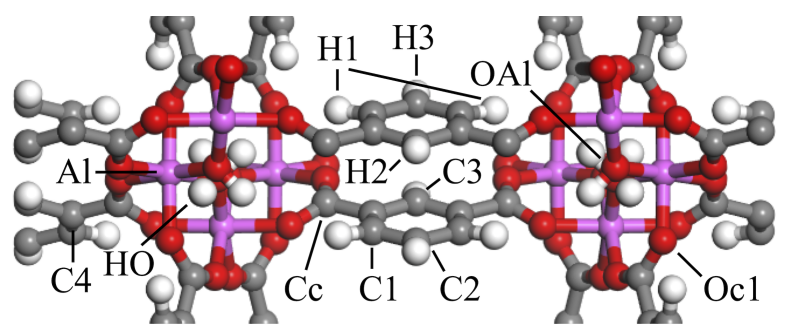

Figure S5: Atom types used to describe CAU-10.

\begin{tabular}{c|ccc|c}
\hline Atom Type & $\begin{array}{c}\text { L-J well depth } \\
{[\mathrm{K}]}\end{array}$ & $\begin{array}{c}\text { L-J distance } \\
{[\AA]}\end{array}$ & partial charge & $\begin{array}{c}\text { Mulliken charge } \\
\left.\text { (Cadiau et al. }{ }^{2}\right)\end{array}$ \\
\hline C1 & 47.856 & 3.473 & -0.073 & -0.0721 \\
C2 & 47.856 & 3.473 & -0.096 & -0.0721 \\
C3 & 47.856 & 3.473 & -0.080 & -0.0721 \\
C4 & 47.856 & 3.473 & -0.061 & -0.0721 \\
Cc & 47.856 & 3.473 & 0.551 & 0.5697 \\
Oc & 48.158 & 3.033 & -0.538 & -0.5554 \\
OAl & 30.213 & 3.118 & -0.713 & -0.7426 \\
H1 & 7.648 & 2.846 & 0.133 & 0.1371 \\
H2 & 7.648 & 2.846 & 0.115 & 0.1371 \\
H3 & 7.648 & 2.846 & 0.165 & 0.1371 \\
HO & 22.142 & 2.571 & 0.297 & 0.3140 \\
Al & 254.127 & 4.008 & 1.362 & 1.3950 \\
\hline
\end{tabular}

Table S8: Interaction parameters for the atom types in CAU-10 and comparison of the used partial charges with values from Cadiau et al. ${ }^{2}$ provided by Guillaume Maurin. 


\section{S5 Monte Carlo Cycles}

\begin{tabular}{l|rc}
\hline $\begin{array}{c}\text { Pressure Range } \\
{[\mathrm{Pa}]}\end{array}$ & Equilibration & Production \\
\hline $0.01-1000$ & 1700000 & 100000 \\
1100 & 1850000 & 100000 \\
1300 & 4850000 & 100000 \\
$1500-3500$ & 1600000 & 100000 \\
\hline
\end{tabular}

Table S9: Monte Carlo cycles used for the water adsorption simulation in MOF-5

\begin{tabular}{l|rc}
\hline $\begin{array}{c}\text { Pressure Range } \\
{[\mathrm{Pa}]}\end{array}$ & Equilibration & Production \\
\hline $0.1-700$ & 2750000 & 100000 \\
$725-900$ & 2500000 & 100000 \\
1000 & 1850000 & 100000 \\
$1200-3000$ & 1650000 & 100000 \\
\hline
\end{tabular}

Table S10: Monte Carlo cycles used for the water adsorption simulation in CAU-10 


\section{S6 Equation for Calculating Contact Angles}
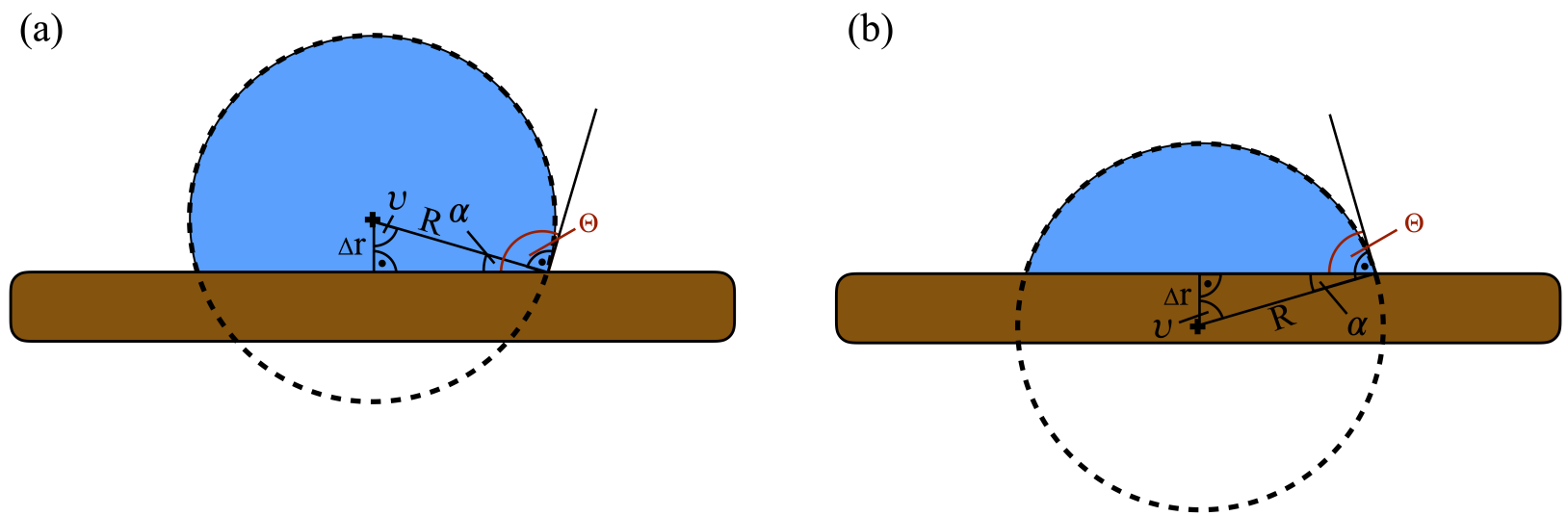

Figure S6: Illustration of how to derive the equation to calculate contact angles for a droplet with its center (a) above or (b) below the interfacial plane.

In (a):

The following holds

$$
\begin{gathered}
\alpha+90^{\circ}=\Theta, \\
\alpha+90^{\circ}+v=180^{\circ} .
\end{gathered}
$$

Hence

$$
v=180^{\circ}-\Theta .
$$

Using the cosine function

$$
\cos v=\cos \left(180^{\circ}-\Theta\right)=\frac{\Delta r}{R},
$$

the contact angle can be calculated by

$$
\Theta=180^{\circ}-\arccos \left(\frac{\Delta r}{R}\right) .
$$

In (b):

The following holds

$$
90^{\circ}=\Theta+\alpha,
$$




$$
\alpha+90^{\circ}+v=180^{\circ} \text {. }
$$

Hence

$$
v=\Theta .
$$

Using the cosine function

$$
\cos v=\cos (\Theta)=\frac{\Delta r}{R},
$$

the contact angle can be calculated by

$$
\Theta=\arccos \left(\frac{\Delta r}{R}\right) .
$$

\section{S7 Density Plots}

(a)

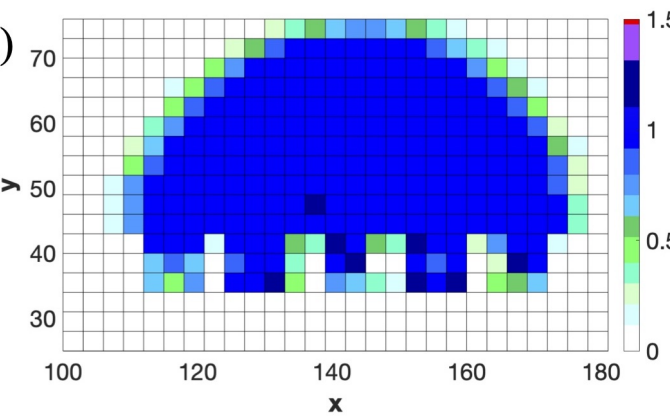

(c)

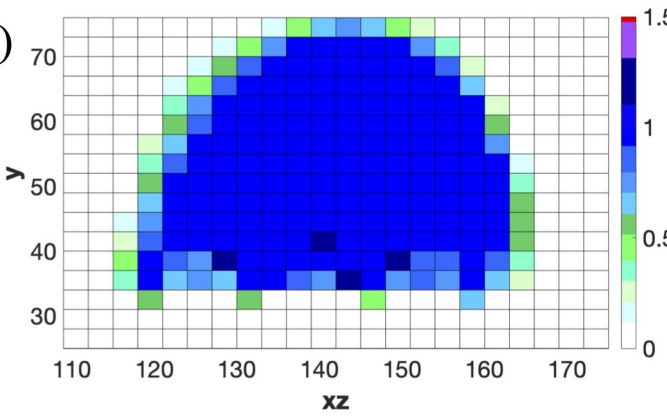

(b)

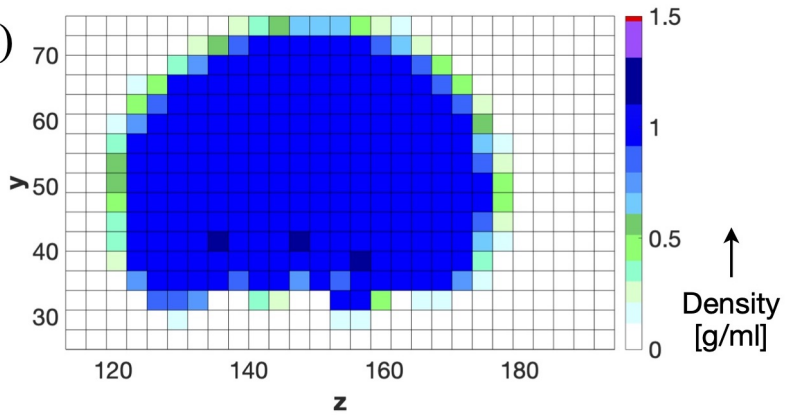

(d)

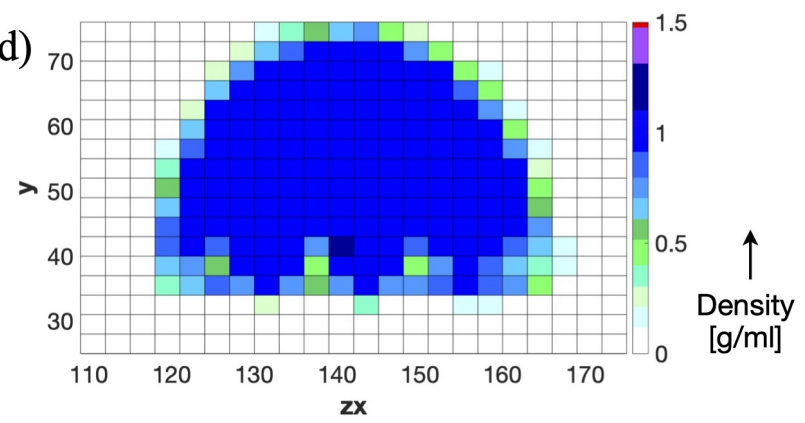

Figure S7: Density plots for the slices (a) Axial 1, (b) Axial 2, (c) Dia1 and (d) Dia2 of MOF-5-phenyl. 

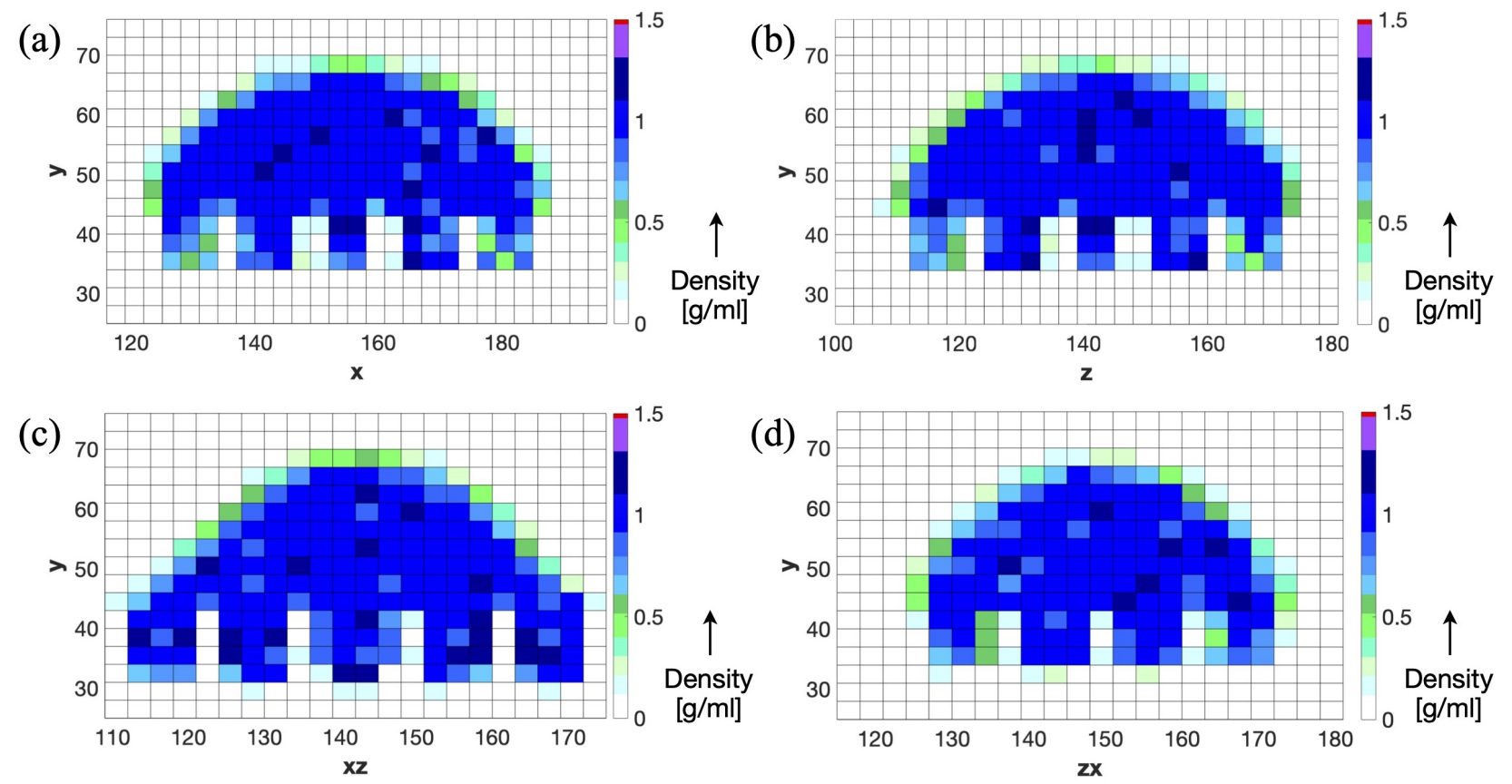

Figure S8: Density plots for the slices (a) Axial 1, (b) Axial 2, (c) Dia1 and (d) Dia2 of MOF-5-benzoic.
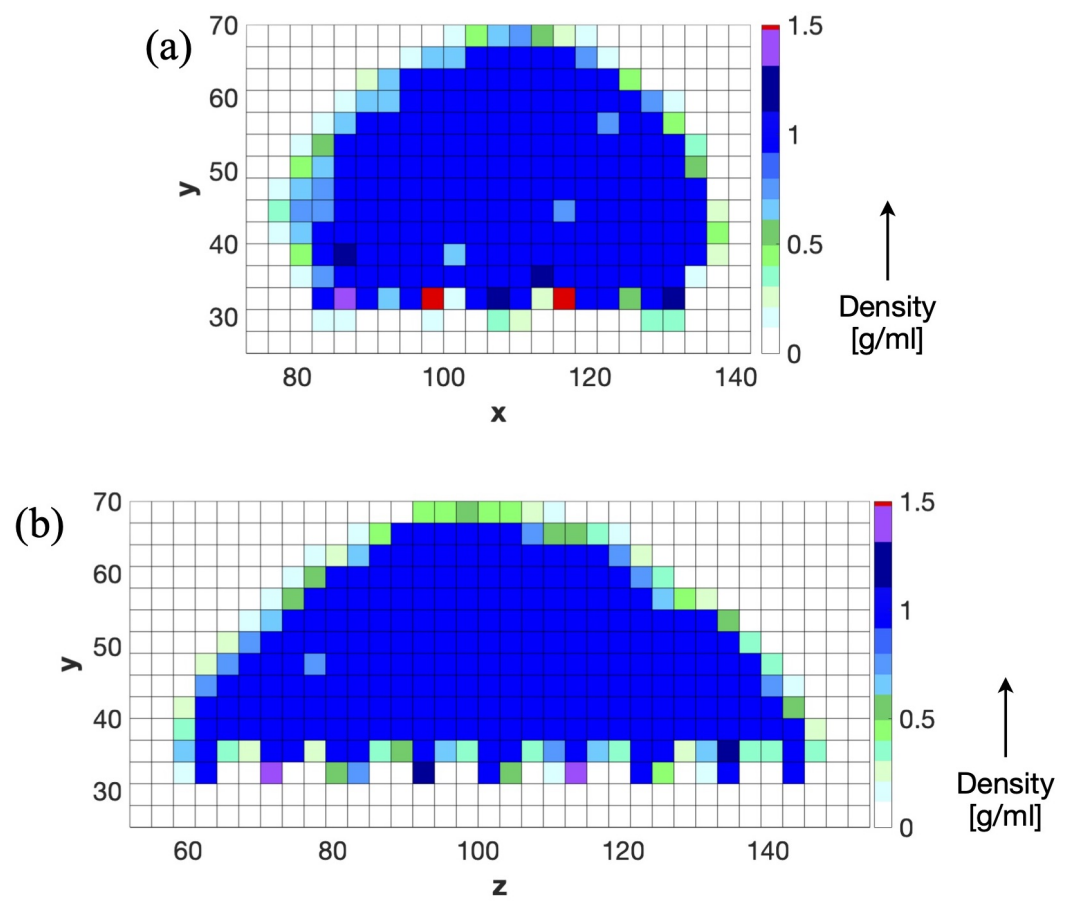

Figure S9: Density plots for the slices (a) Axial 1 and (b) Axial 2 of CAU-10-phenyl 

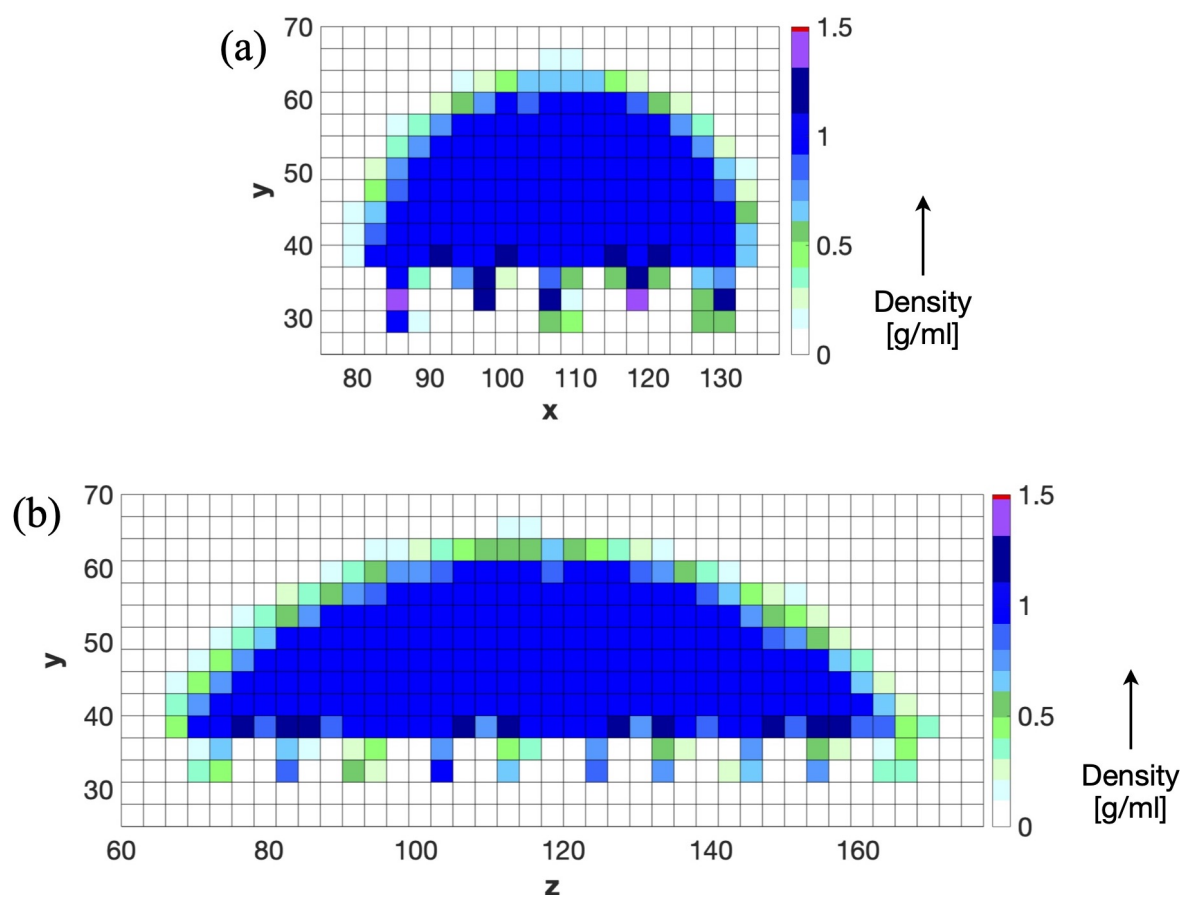

Figure S10: Density plots for the slices (a) Axial 1 and (b) Axial 2 of CAU-10-benzoic

\section{S8 Calculation Data}

\begin{tabular}{c|cc|c|cc}
\hline MOF-5-phenyl & Center & Radius & MOF-5-benzoic & Center & Radius \\
\hline Axial 1 & $40.4 \AA$ & $34.9 \AA$ & Axial 1 & $34.3 \AA$ & $34.1 \AA$ \\
Axial 2 & $46.3 \AA$ & $29.2 \AA$ & Axial 2 & $34.4 \AA$ & $34.3 \AA$ \\
Dia 1 & $42.9 \AA$ & $32.4 \AA$ & Dia 1 & $30.2 \AA$ & $38.7 \AA$ \\
Dia 2 & $42.3 \AA$ & $32.8 \AA$ & Dia 2 & $33.2 \AA$ & $35.0 \AA$ \\
\hline
\end{tabular}

Table S11: Center and radius of the fitted circle for MOF-5-phenyl and MOF-5-benzoic.

\begin{tabular}{c|cc|c|cc}
\hline CAU-10 (Phenyl) & Center & Radius & CAU-10 (Benzoic) & Center & Radius \\
\hline Axial 1 & $27.1 \AA$ & $38.8 \AA$ & Axial 1 & $-3.7 \AA$ & $66.5 \AA$ \\
Axial 2 & $34.1 \AA$ & $32.9 \AA$ & Axial 2 & $35.9 \AA$ & $27.4 \AA$ \\
\hline
\end{tabular}

Table S12: Center and radius of the fitted circle for CAU-10-phenyl and CAU-10-benzoic. 


\section{S9 Finite-Size Effect}

The size of the simulation box should be sufficiently large to minimize interactions between the droplet and molecules inside the periodic images of the simulation box. To confirm that the used simulation box is sufficiently large, we estimate the force $F_{\text {d2i }}$ between two oxygen atoms within two water molecules, one inside the droplet and the other one inside its periodic image, relative to the (Coulomb) force $F_{\mathrm{n}}$ that two oxygen atoms of adjacent water molecules in the droplet exert on each other.

For our estimation, we use the results obtained for CAU-10-benzoic, which exhibits the largest spread in z-direction of about $100 \AA$ (see Figure S10). Given the spread of the droplet of about $100 \AA$, the minimum distance $r_{i j, \mathrm{~d} 2 \mathrm{i}}$ between two water molecules in the droplet and its periodic image is $106 \AA$ (surface model length in $z: 206 \AA$ ). Because the distance of $106 \AA$ is beyond the cut-off distance used to truncate the van-der-Waals interactions, only electrostatic interactions between the oxygen atoms of the water molecules need to be considered. Electrostatic forces $\mathcal{F}_{\text {elec }}$ between two atoms $i$ and $j$ are described by Coulombs law

$$
F_{\text {elec }}=\frac{1}{4 \pi \varepsilon_{0}} \frac{q_{i} q_{j}}{r_{i j}^{2}},
$$

where $\varepsilon_{0}$ is the vacuum electric permittivity, $r_{i j}$ the distance between $i$ and $j$ and $q_{i}$ and $q_{j}$ are the partial charges of atoms $i$ and $j$. The relative force $F_{\mathrm{d} 2 \mathrm{i}} / F_{\mathrm{n}}$ can hence be computed by

$$
\frac{F_{\mathrm{d} 2 \mathrm{i}}}{F_{\mathrm{n}}}=\frac{r_{i j, \mathrm{n}}^{2}}{r_{i j, \mathrm{~d} 2 \mathrm{i}}^{2}},
$$

where $r_{i j, \mathrm{n}}$ is the average distance of an adjacent water molecule inside the droplet obtained by the radial distribution function plotted in Fig. S11. Using Eq. (12), the relative force $F_{\text {d2i }} / F_{\text {n }}$ is given by

$$
\frac{F_{\mathrm{d} 2 \mathrm{i}}}{F_{\mathrm{n}}}=\frac{(2.7 \AA)^{2}}{(106 \AA)^{2}} \approx 0.06 \% \text {. }
$$


The maximal force exerted to an oxygen atom in the droplet by the nearest image of an oxygen atom in an adjacent image of the droplet is hence less than $0.1 \%$ of the (Coulomb) force exerted by an oxygen atom in an adjacent water molecule in the droplet and indicates that the simulation box is sufficiently large to neglect interactions beyond the simulation box boundaries.

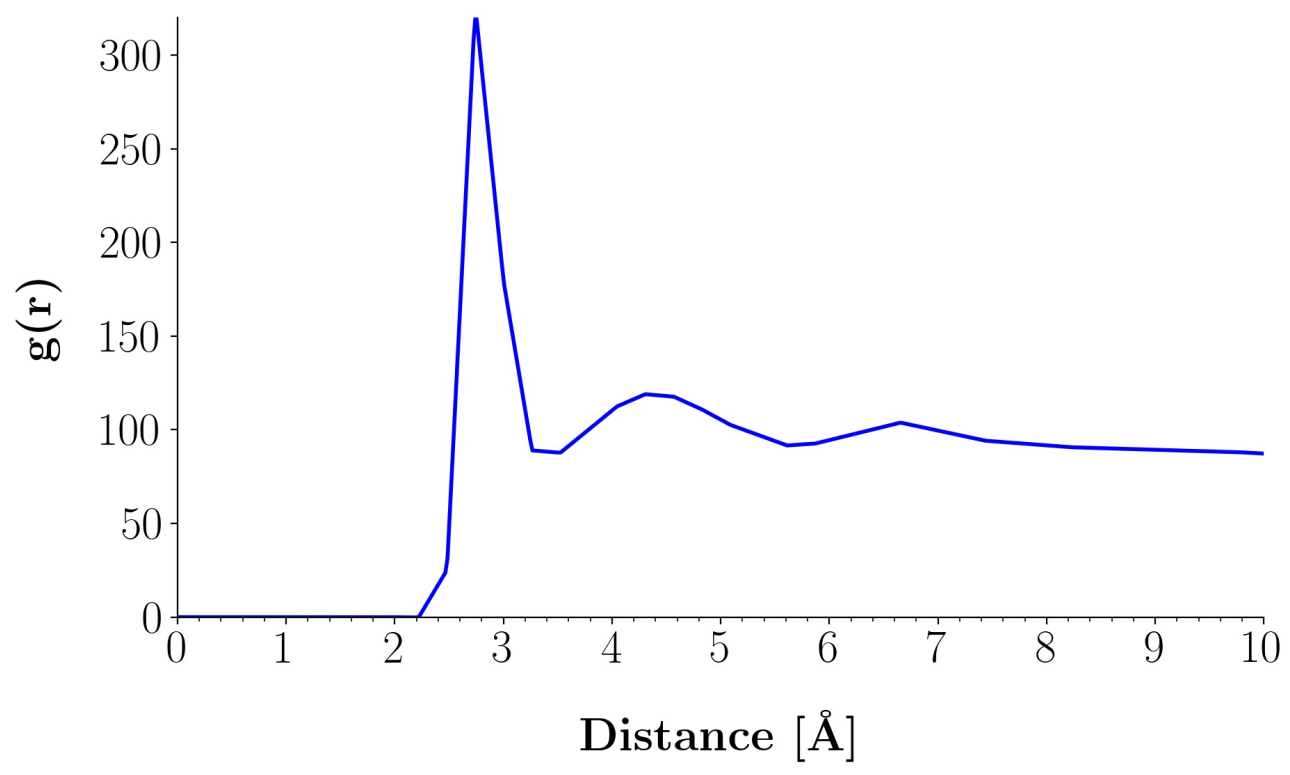

Figure S11: Radial distribution function $\mathrm{g}(\mathrm{r})$ of oxygen in water molecules inside the droplet averaged over $10^{5}$ time steps. Radial distribution functions are defined as the density at a distance $r$ from any atom normalized by the density of an ideal gas at $r$ with the same total density. For homogeneous systems the radial distribution function approaches one. ${ }^{3}$ This does not hold in case of droplet simulations, because a system containing a tiny droplet in a huge simulation box is not a homogeneous system. 


\section{S10 Adsorption Isotherms}
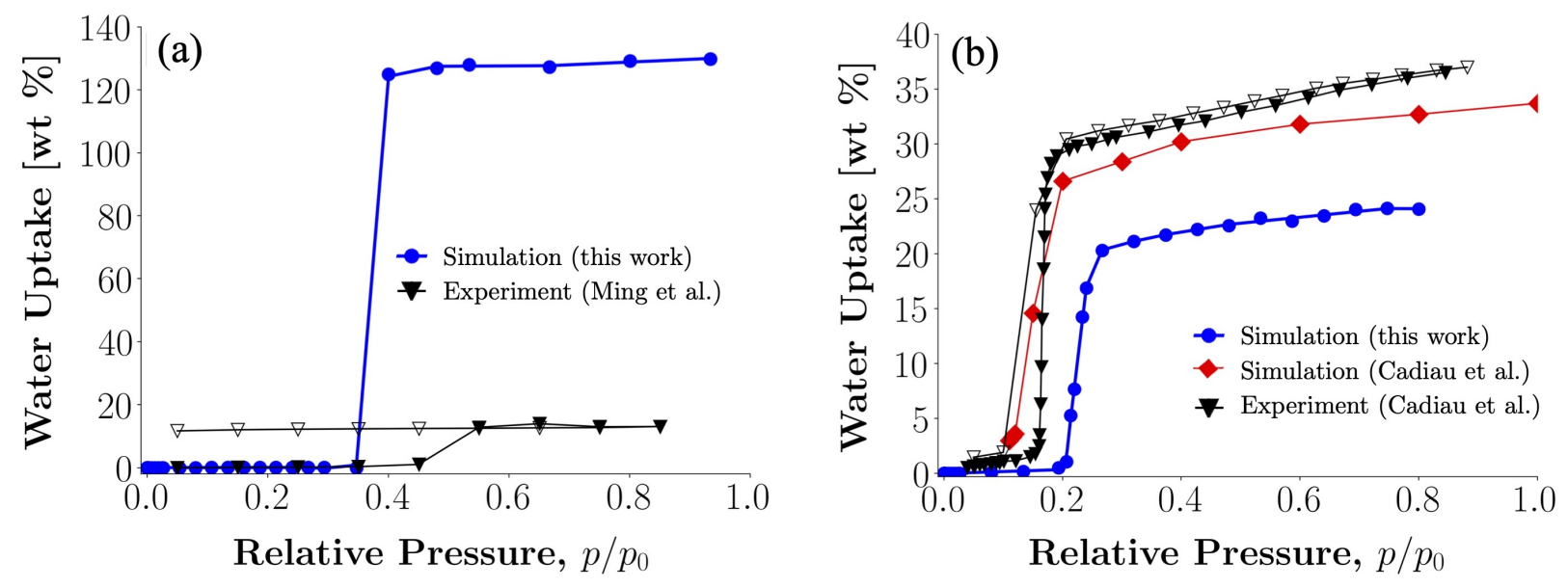

Figure S12: (a) Comparison of the simulated adsorption isotherm of MOF-5 with the simulated adsorption isotherm of MOF-5 and the experimental adsorption isotherm measured by Ming et al. ${ }^{4}$ (b) Comparison of the simulated adsorption isotherm of CAU-10 with the simulated and experimental adsorption isotherm by Cadiau et al. ${ }^{2}$ The isotherm points were determined from the figures in the respective publications. The difference in the adsorption isotherms of Cadiau et al. and this work is due to the different force fields used. Full symbols indicate the adsorption branch, while empty symbols indicate the desorption branch of the isotherm. 


\section{S11 Adsorption Surfaces}

(a)

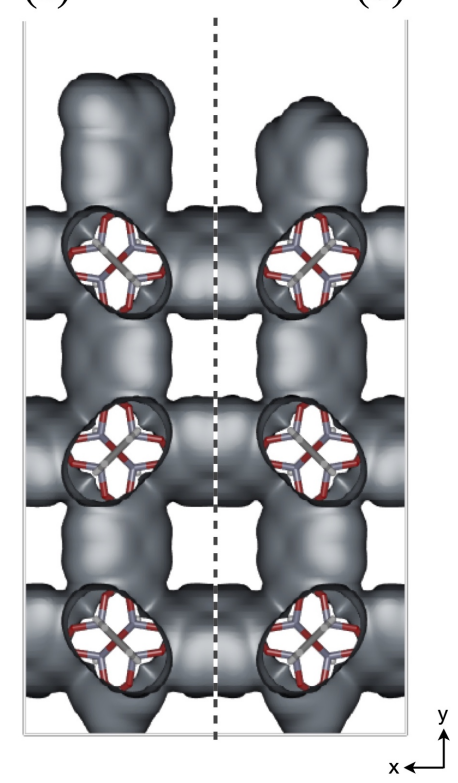

(b) (c)

(d)

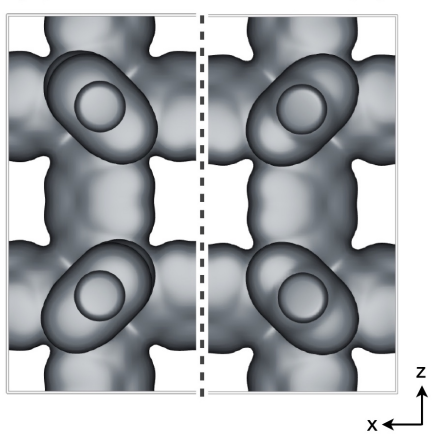

Figure S13: Water adsorption surfaces of the surface modules of (a, c) MOF-5-benzoic and (b, d) MOF-5-phenyl from different perspectives. Generated with iRASPA. ${ }^{5}$

\section{References}

(1) Sladekova, K.; Campbell, C.; Grant, C.; Fletcher, A. J.; Gomes, J. R. B.; Jorge, M. The effect of atomic point charges on adsorption isotherms of $\mathrm{CO}_{2}$ and water in metal organic frameworks. Adsorption 2020, 26, 663-685.

(2) Cadiau, A.; Lee, J. S.; Borgesa, D. D.; Fabry, P.; Devic, T.; Wharmby, M. T.; Martineau, C.; Foucher, D.; Taulelle, F.; Jun, C.-H.; Hwang, Y. K.; Stock, N.; Lange, M. F. D.; Kapteijn, F.; Gascon, J.; Maurin, G.; Chang, J.-S.; Serre, C. Design of Hydrophilic Metal Organic Framework Water Adsorbents for Heat Reallocation. Adv. Mater. 2015, $27,4775-4780$.

(3) Frenkel, D.; Smit, B. Understanding Molecular Simulation: From Algorithms to Applications; Academic Press: San Diego, 2001; Vol. 1; p 85. 
(4) Ming, Y.; Purewal, J.; Yang, J.; Xu, C.; Soltis, R.; Warner, J.; Veenstra, M.; Gaab, M.; Müller, U.; Siegel, D. J. Kinetic Stability of MOF-5 in Humid Environments: Impact of Powder Densification, Humidity Level, and Exposure Time. Langmuir 2015, 31, 49884995.

(5) Dubbeldam, D.; Calero, S.; Vlugt, T. J. iRASPA: GPU-accelerated visualization software for materials scientists. Molecular Simulation 2018, 44, 653-676. 